\title{
Satellite measurements of the global mesospheric sodium layer
}

\author{
Z. Y. Fan ${ }^{1}$, J. M. C. Plane ${ }^{2}$, J. Gumbel ${ }^{3}$, J. Stegman ${ }^{3}$, and E. J. Llewellyn ${ }^{4}$ \\ ${ }^{1}$ School of Environmental Sciences, University of East Anglia, Norwich NR4 7TJ, UK \\ ${ }^{2}$ School of Chemistry, University of Leeds, Leeds, LS2 9JT, UK \\ ${ }^{3}$ Department of Meteorology, Stockholm University, 10691 Stockholm, Sweden \\ ${ }^{4}$ ISAS, Department of Physics and Engineering Physics, University of Saskatchewan, Saskatoon, SK S7N 5E2, Canada
}

Received: 29 March 2007 - Published in Atmos. Chem. Phys. Discuss.: 25 April 2007

Revised: 19 July 2007 - Accepted: 2 August 2007 - Published: 6 August 2007

\begin{abstract}
Optimal estimation theory is used to retrieve the absolute $\mathrm{Na}$ density profiles in the mesosphere/lower thermosphere from limb-scanning measurements of the Na radiance at $589 \mathrm{~nm}$ in the dayglow. Two years of observations (2003 and 2004), recorded by the OSIRIS spectrometer on the Odin satellite, have been analysed to yield the seasonal and latitudinal variation of the $\mathrm{Na}$ layer column abundance, peak height, and peak width. The layer shows little seasonal variation at low latitudes, but the winter/summer ratio increases from a factor of $\sim 3$ at mid-latitudes to $\sim 10$ in the polar regions. Comparison of the measurements made at about 06:00 and 18:00 LT shows little diurnal variation in the layer, apart from the equatorial region where, during the equinoxes, there is a two-fold increase in Na density below $94 \mathrm{~km}$ between morning and evening. This is most likely caused by the strong downward wind produced by the diurnal tide between $\sim 02: 00$ and 10:00 LT. The dramatic removal of $\mathrm{Na}$ below $85 \mathrm{~km}$ at latitudes above $50^{\circ}$ during summer is explained by the uptake of sodium species on the ice surfaces of polar mesospheric clouds, which were simultaneously observed by the Odin satellite.
\end{abstract}

\section{Introduction}

Meteoric ablation is the source of the layer of neutral sodium atoms that occurs globally in the upper mesosphere/lower thermosphere (MLT) between 80 and $105 \mathrm{~km}$ (Plane, 2003). The Na layer was discovered nearly 80 years ago: radiation at $589 \mathrm{~nm}$ was observed in the night sky spectrum (Slipher, 1929), and later identified as emission from neutral sodium atoms within the atmosphere (Bernard, 1939). In the 1950s, the layer was observed from resonance fluorescence at $589 \mathrm{~nm}\left(\mathrm{Na}\left(3^{2} \mathrm{P}_{J}-3^{2} \mathrm{~S}_{1 / 2}\right)\right)$ during twilight (Hunten,

Correspondence to: J. M. C. Plane

(j.m.c.plane@leeds.ac.uk)
1967). The variation of the fluorescence signal as the solar terminator passed through the layer enabled the layer profile to be determined. The absolute $\mathrm{Na}$ abundance was estimated by performing radiative transfer calculations on the measured Na resonant scattering signal (Hunten, 1954; Chamberlain, 1956; Hunten, 1967).

Measurements of the Na $D$-line emission in the dayglow were then performed using a Zeeman photometer, which utilized an oscillating magnetic field around a sodium vapour cell to filter out the Na $D$-line spectrum and hence discriminate against Rayleigh-scattered sunlight (Blamont and Donahue, 1961). The Na layer was also studied during the day by ground-based photometric measurements of atomic $\mathrm{Na}$ absorption (Chamberlain, 1956), and by rocket-borne photometric measurements of the dayglow (Donahue and Meier, 1967). However, because of the passive mode of photometric measurements, where solar radiation is the only excitation source, the observations were confined to the twilight or dayglow.

The invention of the tunable laser enabled enormous progress to be made with the development of the lidar (light detection and ranging) technique in the late 1960s (Bowman et al., 1969). Lidar provided many advantages over photometers. Firstly, by active excitation of the atmospheric $\mathrm{Na}$, observations could be performed over a full diurnal cycle: initially, night-time measurements were performed (Gibson and Sandford, 1971), but modified receivers to exclude scattered sunlight then enabled daytime measurements to be made (Gibson and Sandford, 1972). These measurements quickly showed that the apparent enhancement of the $\mathrm{Na}$ layer during daytime, reported from photometric measurements of the dayglow (Blamont and Donahue, 1961), was not correct. Long-term observations of the Na layer provided more details of seasonal, latitudinal and diurnal variations (e.g. Megie and Blamont, 1977; Clemesha et al., 1979; Kirchhoff and Clemesha, 1983; Gardner et al., 1988; Tilgner and von Zahn, 1988; von Zahn et al., 1988; Plane et al., 1999;

Published by Copernicus Publications on behalf of the European Geosciences Union. 


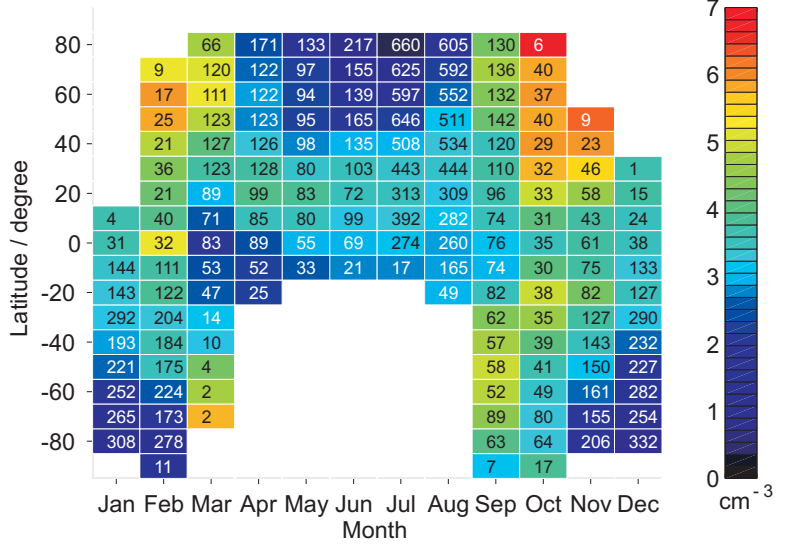

Fig. 1. Grid plot of the monthly-averaged total Na column density (units: atom $\mathrm{cm}^{-2}$ ), zonally averaged in $10^{\circ}$ latitude bins. The data is compiled from OSIRIS limb-scanning radiance measurements during 2003 and 2004. The number inside each grid box is the number of integrated $\mathrm{Na}$ profiles that were averaged to yield the mean column density.

She et al., 2000; Clemesha et al., 2004; Gardner et al., 2005). Of course, an important limitation with lidar measurements is that the instruments are usually ground-based, and thus provide only localized coverage (airborne lidars partially overcome this difficulty (Kane et al., 1991; Plane et al., 1998), but only for short campaigns). Global coverage can only be provided by space-borne instruments. In fact, the first satellite-borne observations of the sodium nightglow were made two decades ago (Newman, 1988), although the conclusions of that study were subsequently criticized (Clemesha et al., 1990). The Na nightglow is generated from a chemiluminescent cycle involving $\mathrm{Na}, \mathrm{O}_{3}$ and $\mathrm{O}$ (Chapman, 1939), and so the complication of using nightglow observations is that the $\mathrm{Na}$ atom density is derived indirectly (Xu et al., 2005). Recently, Fussen et al. reported global measurements of the mesospheric Na layer by the GOMOS stellar occultation instrument (i.e., the Na density was measured by atomic absorption) on the ENVISAT satellite (Fussen et al., 2004). Unfortunately, as we will discuss below, the retrieved $\mathrm{Na}$ column abundances, layer density profiles, and the seasonal and latitudinal variations are in poor agreement with the available data from ground-based lidars.

We have recently developed a new method (Gumbel et al., 2007) using optimal estimation theory (Rodgers, 2000) to retrieve the absolute mesospheric Na density profile from limb-scanning satellite observations of the $\mathrm{Na} D$-lines in the dayglow. The method has been validated by comparing $\mathrm{Na}$ profiles, retrieved from the OSIRIS spectrometer on the Odin satellite, with profiles measured during overflights of the $\mathrm{Na}$ lidar at Ft. Collins, Colorado. The details of the methodology and error characterization are contained in our earlier paper (Gumbel et al., 2007). OSIRIS measures irradiance in the limb at wavelengths between 280 and $800 \mathrm{~nm}$, with a resolution of $\sim 1 \mathrm{~nm}$ (Llewellyn et al., 2004). Odin is in a Sun-synchronous orbit at a height of $\sim 600 \mathrm{~km}$, with an ascending node at $\sim 18: 00 \mathrm{~h}$ local time (LT) and descending node at $\sim 06: 00$ LT (Murtagh et al., 2002).

In this paper, we have used this method to analyse two years of Odin data (2003 to 2004), in order to obtain the global seasonal distribution of the Na layer. During these two years there was a high frequency of mesospheric measurements in July/August, because during these northern hemisphere summer periods Odin was dedicated to observing polar mesospheric clouds (PMCs) by limb-scanning between 70 and $110 \mathrm{~km}$.

\section{Global latitudinal and seasonal variations}

Figure 1 illustrates the global coverage of the retrieved $\mathrm{Na}$ total abundance or column density (in units of $\mathrm{Na}$ atom $\mathrm{cm}^{-2}$ ), where the retrieved $\mathrm{Na}$ density profiles have been integrated from 70 to $120 \mathrm{~km}$. The data is zonally averaged to increase the data available in some latitude bins. In order to avoid artefactual distortions introduced by contouring the data, this map is plotted in a grid format, with each grid box corresponding to $10^{\circ}$ in latitude. The number inside each grid box indicates the number of integrated $\mathrm{Na}$ density profiles that have been averaged to produce the resulting column density. The blank grid boxes show occasions when mesospheric dayglow measurements could not be made because the solar zenith angle was larger than $92^{\circ}$. This occurred in the winter hemisphere at mid- to high latitudes. The blank grid boxes at very high latitudes $\left(>85^{\circ}\right)$ occur because of these regions are not covered by the satellite orbits.

As many previous ground measurements have reported, the $\mathrm{Na}$ layer exhibits seasonal variations at all latitudes higher than $20^{\circ}$ : the total $\mathrm{Na}$ column density decreases to a minimum near the summer solstice and reaches a maximum in early winter. During mid-summer and the whole winter period, the $\mathrm{Na}$ abundance exhibits relatively small fluctuations compared with the much greater variability during the spring and autumn equinoxes. Figure 1 shows that the seasonal variation from summer minimum to winter maximum becomes larger at higher latitudes. Although the data from mid-winter months is absent (except at low latitudes), we can still estimate the seasonal ratio by employing the available data from late autumn/early winter. The data in Fig. 1 is in good accord with ground-based measurements at $\sim 40^{\circ} \mathrm{N}$ (Megie and Blamont, 1977; Plane et al., 1999; States and Gardner, 1999; She et al., 2000), at $51^{\circ} \mathrm{N}$ (Gibson and Sandford, 1971), at $23^{\circ} \mathrm{S}$ (Clemesha et al., 1979), at $43^{\circ} \mathrm{S}$ (Hunten, et al., 1964), and at $90^{\circ} \mathrm{S}$ (Gardner et al., 2005). The maximum $\mathrm{Na}$ layer density usually occurs in OctoberNovember in the northern hemisphere ( $\mathrm{NH})$, and from May to August in the southern hemisphere ( $\mathrm{SH})$. At low latitudes, this ratio is $\sim 2$, and rises to $\sim 3$ at middle latitudes. In polar 
region, this ratio increases up to nearly 10 . The minimum monthly averaged $\mathrm{Na}$ abundance in Fig. 1 occurs in July at $80^{\circ} \mathrm{N}$, and the maximum is during October at $80^{\circ} \mathrm{N}$. In the equatorial region $\left( \pm 10^{\circ}\right)$, by contrast, the seasonal variations are very small: the seasonal transitions between northern and southern hemisphere merge here, with a minimum in about March/April and a maximum in January/February. The seasonal ratio is typically no more than 1.5 .

In order to understand the seasonal variation and latitudinal distribution of the $\mathrm{Na}$ abundance, we need to consider mesospheric sodium chemistry. In the mesosphere and lower thermosphere (MLT), $\mathrm{Na}^{+}$ions and sodium bicarbonate $\left(\mathrm{NaHCO}_{3}\right)$ are the major reservoir species above and below the atomic Na layer, respectively (Plane et al., 1999; Plane, 2004). Due to the long residence time ( $\sim 7$ days) of ablated sodium in the region between 80 and $100 \mathrm{~km}$ (Plane, 2004), and the comparatively short lifetimes of the ratedetermining chemical reactions that convert sodium between atomic $\mathrm{Na}$ and these reservoirs, the chemistry reaches a photochemical steady-state on the timescale of vertical transport by eddy or molecular diffusion (Plane et al., 1998). Consequently, atmospheric chemistry plays a key role in determining the atomic $\mathrm{Na}$ distribution. $\mathrm{Na}$ is converted to $\mathrm{NaHCO}_{3}$ via the following sequence of reactions (Plane, 2004):

$\mathrm{Na}+\mathrm{O}_{3} \rightarrow \mathrm{NaO}+\mathrm{O}_{2}$

$\mathrm{NaO}+\mathrm{H}_{2} \mathrm{O} \rightarrow \mathrm{NaOH}+\mathrm{OH}$

$\mathrm{NaOH}+\mathrm{CO}_{2}(+\mathrm{M}) \rightarrow \mathrm{NaHCO}_{3}\left(\mathrm{M}=\mathrm{N}_{2}\right.$ or $\left.\mathrm{O}_{2}\right)$

All of these reactions are fast, with small temperature dependences. $\mathrm{NaHCO}_{3}$ is converted back to $\mathrm{Na}$ by the reaction:

$\mathrm{NaHCO}_{3}+\mathrm{H} \rightarrow \mathrm{Na}+\mathrm{H}_{2} \mathrm{CO}_{3}$

In contrast, this reaction has a large activation energy (Cox et al., 2001); that is, at higher temperatures it becomes much faster, and the steady-state balance shifts from $\mathrm{NaHCO}_{3}$ to $\mathrm{Na}$. A secondary effect is that $\mathrm{O}_{3}$ forms from the recombination of $\mathrm{O}$ and $\mathrm{O}_{2}$, and this reaction gets slower at higher temperatures: the result is that smaller $\mathrm{O}_{3}$ concentrations slow down the conversion of $\mathrm{Na}$ to $\mathrm{NaO}$, and the larger $\mathrm{O}$ concentrations reduce $\mathrm{NaO}$ back to $\mathrm{Na}$, enhancing the effect of Reaction (4) becoming faster. At high latitudes, several factors further reinforce the positive temperature dependence of the $\mathrm{Na}$ density below $96 \mathrm{~km}$. The first of these is the removal of sodium species on the ice surfaces of PMCs, which form between 82 and $85 \mathrm{~km}$ during summer at high latitudes when the temperature decreases below $\sim 150 \mathrm{~K}$ (Gardner et al., 2005; Murray and Plane, 2005; She et al., 2006). These low temperatures are caused by upwelling air (via adiabatic expansion) which also transports $\mathrm{H}_{2} \mathrm{O}$ from the lower mesosphere to above $80 \mathrm{~km}$ (Livesey et al., 2003), thereby increasing the rate at which $\mathrm{Na}$ is converted to $\mathrm{NaHCO}_{3}$ (Reaction 2). Conversely, during winter there is strong downward transport caused by the convergence of the meridional wind

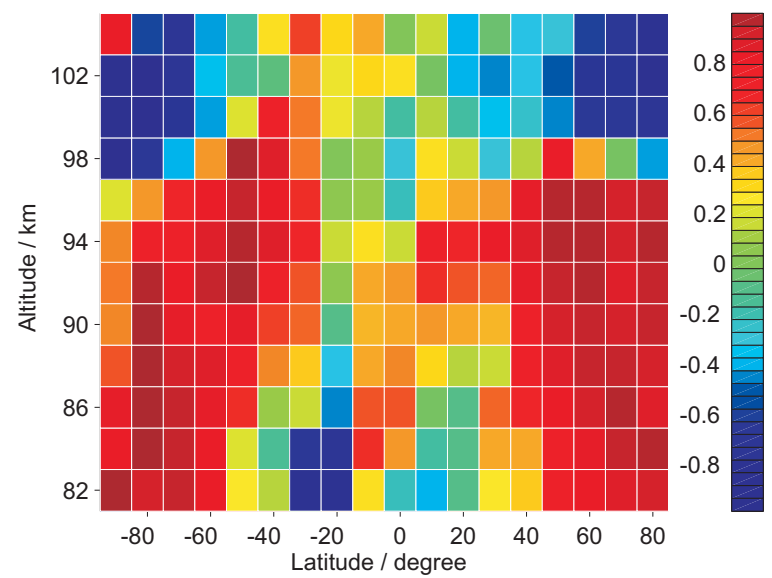

Fig. 2. Grid plot of the correlation coefficient between the NRLMSISE-00 model temperature (Picone et al., 2002) and the retrieved $\mathrm{Na}$ density, versus latitude and altitude.

at the winter pole (Gardner et al., 2005; Portnyagin et al., 2004), which has two effects: the temperature increases because of adiabatic heating, and $\mathrm{Na}$ is transported downwards from the peak of the layer. Figure 2 illustrates the latitudinal distribution of the correlation coefficient between the retrieved $\mathrm{Na}$ density and temperature (taken from the MSIS model, Picone et al., 2002), as a function of height. At middle and high latitudes, a strong positive correlation between temperature and $\mathrm{Na}$ density is seen below $96 \mathrm{~km}$. This correlation is expected in view of the effects of temperature on the neutral sodium chemistry (see above), and has also been seen in mid-latitude lidar data (Plane et al., 1999).

At altitudes above $96 \mathrm{~km}$, the correlation coefficient abruptly turns negative. This is because ion chemistry dominates on the topside of the $\mathrm{Na}$ layer. $\mathrm{Na}^{+}$ions are formed by charge transfer with ambient $\mathrm{NO}^{+}$and $\mathrm{O}_{2}^{+}$ions and, to a lesser extent, by photo-ionization (Plane, 2004). These processes are essentially temperature-independent. In contrast, the neutralization of $\mathrm{Na}^{+}$begins by forming a cluster ion with $\mathrm{N}_{2}$ :

$\mathrm{Na}^{+}+\mathrm{N}_{2}(+\mathrm{M}) \rightarrow \mathrm{Na}^{+} \cdot \mathrm{N}_{2}$, where $\mathrm{M}=\mathrm{N}_{2}$ or $\mathrm{O}_{2}$

This cluster ion can switch with more stable ligands such as $\mathrm{CO}_{2}$ or $\mathrm{H}_{2} \mathrm{O}$, or be reduced back to $\mathrm{Na}^{+}$by atomic $\mathrm{O}$, which slows the overall process (Cox and Plane, 1998). However, the cluster ions eventually undergo dissociative electron recombination to yield $\mathrm{Na}$. Reaction (5) is an association reaction with a negative temperature dependence (Cox and Plane, 1998): that is, at lower temperatures the cluster ions form more rapidly, and so the steady-state balance between $\mathrm{Na}^{+}$ and $\mathrm{Na}$ shifts towards the neutral atom.

At low latitudes $\left( \pm 20^{\circ}\right)$, the Na density does not exhibit a consistently strong correlation with temperature either below or above $96 \mathrm{~km}$. In contrast, there is a strong diurnal variation 

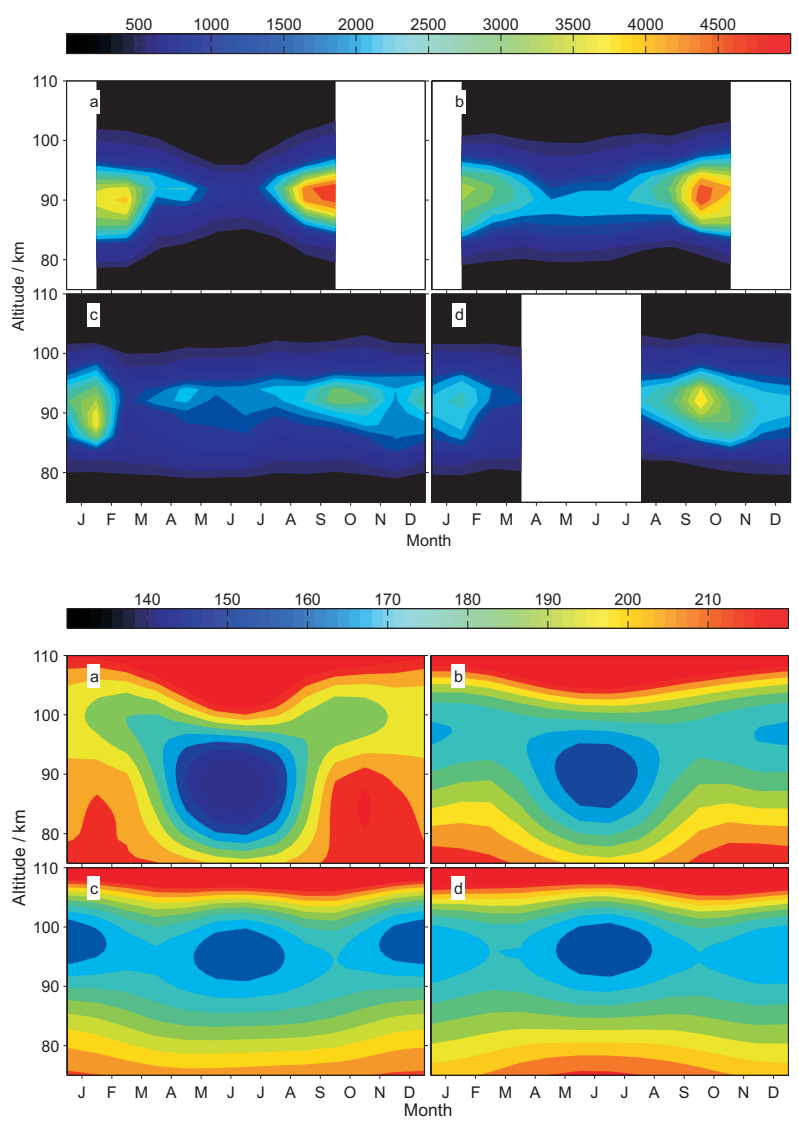

Fig. 3. Seasonal variation of the zonally- averaged Na density profile (top panel, units: atom $\mathrm{cm}^{-3}$ ), and the NRLMSISE-00 atmosphere temperature profiles (Picone et al., 2002) (bottom panel, units: $\mathrm{K}$ ), from $75 \mathrm{~km}$ to $110 \mathrm{~km}$ at four latitude bands centred at (a) $70^{\circ} \mathrm{N}$, (b) $40^{\circ} \mathrm{N}$, (c) the equator, and (d) $20^{\circ} \mathrm{S}$.

in this region which appears to be driven by the diurnal tide (see below).

Figure 3 illustrates the seasonal variability of the Na layer: the top panel shows the monthly Na profiles, zonally averaged in four latitude bands. The corresponding monthly temperature profiles are shown in the bottom panel. Once again, the positive correlation between $\mathrm{Na}$ and temperature below $96 \mathrm{~km}$, and the anti-correlation above this altitude, is clearly visible at latitudes higher than $20^{\circ} \mathrm{N}$ and S. Figure 3a shows the seasonal variation of the $\mathrm{Na}$ density in the $\operatorname{Arctic}\left(70^{\circ} \mathrm{N}\right)$. Note the removal of $\mathrm{Na}$ on both the top and bottom of the layer during summer, which is much more pronounced than at lower latitudes. As discussed above, the removal on the bottom side is caused by the stability of the chemical reservoir $\mathrm{NaHCO}_{3}$ at lower temperatures. However, this is greatly amplified by the uptake of sodium species on PMC ice particles (discussed in more detail below). Because of vertical mixing, $\mathrm{Na}$ is also removed on the topside of the layer. The seasonal temperature variation becomes smaller at mid- and low latitudes, leading to less removal of $\mathrm{Na}$ during summer.
Figure $3 \mathrm{~b}$ shows the $\mathrm{Na}$ profile at $40^{\circ} \mathrm{N}$. This latitude was chosen for direct comparison with the Na layer seasonal dependence at $40^{\circ} \mathrm{N}$ reported recently from stellar occultation measurements made by the GOMOS instrument on ENVISAT (Fig. 5 in Fussen et al., 2004). There are several major discrepancies with the results of the present study. First, the GOMOS retrievals show a second peak in the Na density during mid-summer, whereas the OSIRIS result is a midsummer minimum, in accord with the lidar observations of the night-time Na layer at Ft. Collins (Colorado) (She et al., 2000) and Urbana (Illinois) (Plane et al., 1999; States and Gardner, 1999). Second, the maximum Na density in the GOMOS retrievals is $\sim 2500 \mathrm{~cm}^{-3}$ in March, compared with just over $5000 \mathrm{~cm}^{-3}$ during October/November for OSIRIS and the mid-latitude lidar observations. Third, the width of the $\mathrm{Na}$ layer retrieved by GOMOS at $40^{\circ} \mathrm{N}$ is highly variable: it is narrowest in March (extending from $85-105 \mathrm{~km}$ ), when the $\mathrm{Na}$ density at the layer peak is largest, and is much broader $(75-110 \mathrm{~km})$ in late summer when the peak density is a minimum. In contrast, Fig. 3b shows that the layer thickness retrieved by OSIRIS at $40^{\circ} \mathrm{N}$ is fairly constant, with the layer being somewhat broader in early winter when the peak density is a maximum (again in good accord with the lidar observations).

The reasons for these very marked discrepancies between the results from OSIRIS and GOMOS are not clear. Although the GOMOS results are for 2003, and the OSIRIS results combine data from 2003 and 2004, there are no significant differences in the OSIRIS Na layer data between these successive years. The OSIRIS measurements were made at 06:00 or 18:00 LT, whereas most of the GOMOS measurements were at around 09:00 or 23:00 LT. This might indicate that some diurnal effect could be responsible for the differences. Indeed, a limited number of GOMOS measurements were made over the whole range of LT, from which the diurnal behaviour of the Na layer could be examined (Fussen et al., 2004). The data showed very little change in the layer at 06:00, 12:00 and 18:00 LT, and then a large decrease, by $\sim 40 \%$ between 70 and $90 \mathrm{~km}$, at 24:00 LT. Strangely, such diurnal behaviour has not been observed by lidars located over a range of latitudes (Gibson and Sandford, 1972; Kirchhoff and Clemesha, 1983; States and Gardner, 1999; She et al., 2000). In conclusion, the GOMOS results are not in accord with either the OSIRIS measurements or ground-based lidars, but it is unclear why this is the case.

Figure 4 illustrates the distribution of the full width at half maximum (FWHM), the peak density, and the peak height of the Na layer, plotted as a function of latitude and month. There parameters are determined from the monthly average profiles in each of the grid boxes. Due to the limited vertical resolution in the retrieved profiles, the parameters cannot be determined with the precision of a ground-based lidar. Nevertheless, interesting results are obtained. Unsurprisingly, the FWHM is a minimum in polar summer, because of removal of $\mathrm{Na}$ on both the top and bottom of the layer (see above), 

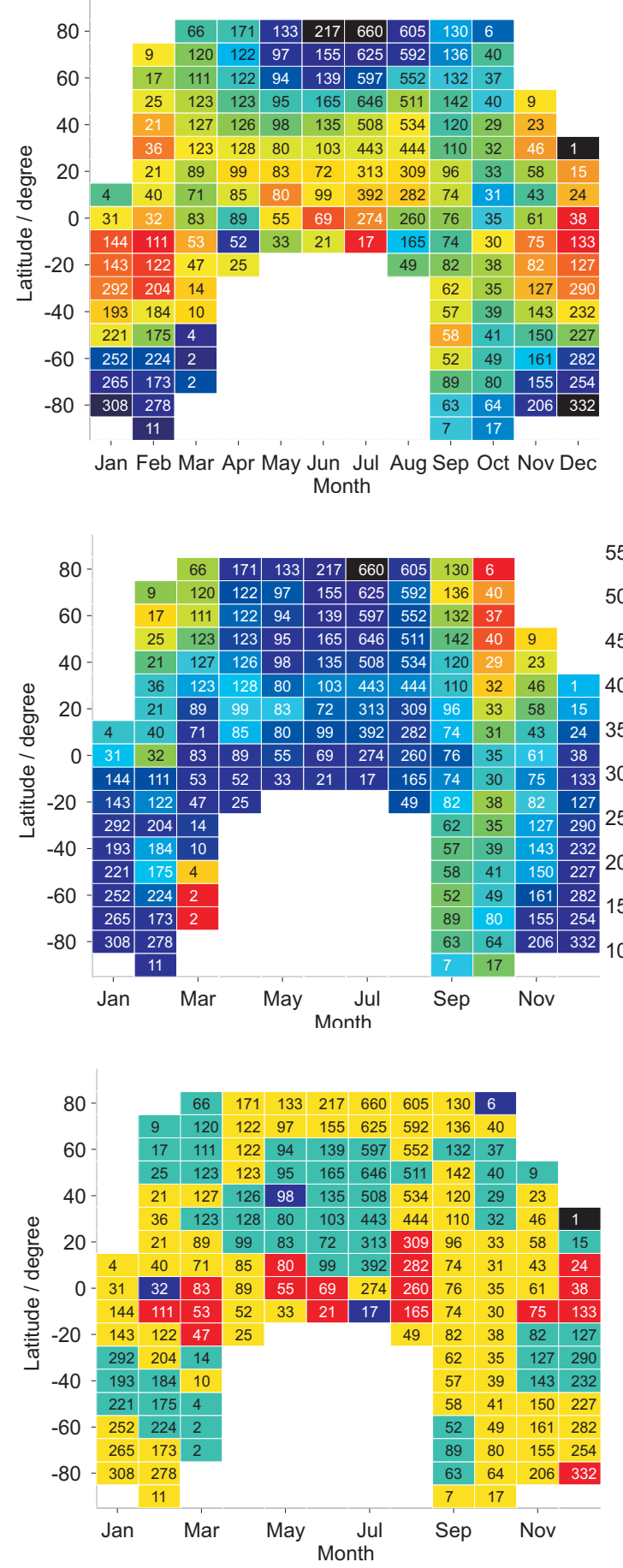

Fig. 4. Top panel: seasonal variation of the full width at half maximum of the $\mathrm{Na}$ layer (in $\mathrm{km}$ ), as a function of latitude and month. Middle panel: seasonal variation of the peak density (in atom $\mathrm{cm}^{-3}$ ), as a function of latitude and month. Bottom panel: seasonal variation of the peak height of the Na layer (in $\mathrm{km}$, with $\pm 1 \mathrm{~km}$ uncertainty), as a function of latitude and month.

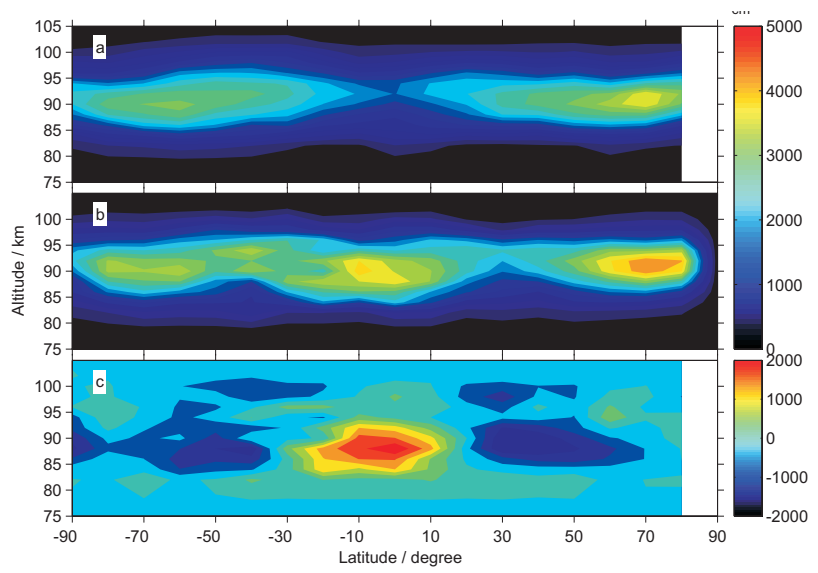

Fig. 5. The zonally-averaged $\mathrm{Na}$ layer (units: atom $\mathrm{cm}^{-3}$ ) in September, as a function of latitude: (a), averaged Na profile around 06:00 LT; (b), averaged Na profile around 18:00 LT; and (c), difference between the evening and morning profiles.

whereas in winter the FWHM approximately doubles (at latitudes above $60^{\circ} \mathrm{N}$ ).

A comparison of the FWHM and peak density in the top and middle panels of Fig. 4, respectively, shows that these parameters are not strongly correlated (as might have been expected). For example, the highest peak densities occur at the autumn equinox above $40^{\circ}$ in both hemispheres, when the layer is actually quite narrow. Moreover, the Na layer tends to be broad at low latitudes (below $40^{\circ}$ ) with a relatively small peak density. The peak height of the layer lies mostly between 90 and $92 \mathrm{~km}$. However, it is often higher $(\sim 94 \mathrm{~km})$ in the equatorial region, as a result of the strong diurnal tide (see below).

\section{Diurnal variation in the equatorial region}

The Odin satellite takes measurements at about 06:00 LT (descending node) and 18:00 LT (ascending node), and the above analyses of seasonal properties of the $\mathrm{Na}$ layer combine the morning and evening observations. Indeed, at midand high latitudes there is no significant diurnal difference. In contrast, a marked difference between the morning and evening profiles is observed in the tropics, especially at the equinoxes. This is illustrated for the month of September in Figs. 5a and $\mathrm{b}$, which show the zonally averaged morning and evening profiles, respectively, and Fig. $5 \mathrm{c}$, which shows the difference between the evening and morning, as a function of latitude. The $\mathrm{Na}$ layer in the tropical region $\left(10^{\circ} \mathrm{N}-15^{\circ} \mathrm{S}\right)$ is strongly depleted in the morning. Most of the depletion occurs below $95 \mathrm{~km}$, peaking at $88 \mathrm{~km}$, and the morning layer column density is about $50 \%$ of that in the evening. A similarly significant diurnal variation in the tropics is seen at the March equinox. In contrast, this diurnal variation becomes 
much smaller at the solstice (the morning column density is $\sim 85 \%$ of that in the evening).

It is interesting to compare the diurnal variation at $23^{\circ} \mathrm{S}$ in the Odin data (Fig. 5c) with lidar measurements made in Brazil at this latitude. These measurements show a predominantly semi-diurnal variation with maxima at 06:00 and 18:00 LT (Clemesha et al., 1982). However, these lidar observations were restricted to winter, whereas the satellite measurements exhibit the relatively modest diurnal variation at $23^{\circ} \mathrm{S}$ during spring and autumn, and in fact show essentially no diurnal variation at the summer solstice (January).

The most likely explanation for the strong diurnal variation seen at the equinoxes is the effect of the diurnal tide (note that because the satellite measurements are made at local times that are $12 \mathrm{~h}$ apart, the effect of the semi-diurnal tide would be hard to observe). Figure 6 shows the latitudinal dependence of the vertical tidal wind velocity at an altitude of $90.6 \mathrm{~km}$ (close to the peak of the Na layer), as a function of local time. This is calculated from the Global Scale Wave Model (GSWM) (Hagan and Forbes, 2002). Although both the diurnal and semi-diurnal tide are included in the GSWM, it is clear from Fig. 6 that the diurnal tide dominates around $90 \mathrm{~km}$. Note that the largest wind velocities are in the tropical region $\left(20^{\circ} \mathrm{N}-20^{\circ} \mathrm{S}\right)$. The strong downward wind, which actually starts around $100 \mathrm{~km}$ at midnight, appears at $91 \mathrm{~km}$ around 04:00 LT, reaches a miximum of $-20 \mathrm{~cm} \mathrm{~s}^{-1}$ around 07:00 LT, and then dissipates after 10:00 LT. Between 14:00 LT and 18:00 LT, when the evening Odin measurements were made, the vertical wind reverses but its velocity is small, between -5 and $+5 \mathrm{~cm} \mathrm{~s}^{-1}$. Interestingly, the vertical wind maximum is slightly asymmetric to the south (peaking at $\sim 5^{\circ} \mathrm{S}$ ), and this may correspond to the asymmetry in the Na diurnal variation which also peaks south of the equator (Fig. 5, lowest panel). This tidal behaviour in the tropics should affect the Na layer in several ways which may explain the diurnal behaviour of the tropical layer (Fig. 5). First, the strong downward wind starting at midnight will cause a vertical displacement of 3-4 km by the time of the Odin measurement at 06:00 LT. Atomic Na, close to the layer peak at $91 \mathrm{~km}$, will be displaced into a region of higher pressure where the termolecular reaction

$\mathrm{Na}+\mathrm{O}_{2}(+\mathrm{M}) \rightarrow \mathrm{NaO}_{2}$

will form sodium superoxide, a reasonably stable reservoir species (Plane, 2004). Reaction (3), which is pressuredependent, will also increase and produce the more stable reservoir $\mathrm{NaHCO}_{3}$.

The strong downward tidal wind also affects the constituents $\mathrm{O}$ and $\mathrm{H}$. For example, during September the atomic $\mathrm{O}$ concentration derived from the Wind Imaging Interferometer (WINDII) on the Upper Atmosphere Research Satellite exhibits a dramatic decrease (by over 50\%) in the equatorial region between 02:00 LT and dawn, at altitudes up to about $95 \mathrm{~km}$ (Russell et al., 2005). Atomic $\mathrm{O}$ and $\mathrm{H}$ exert a major

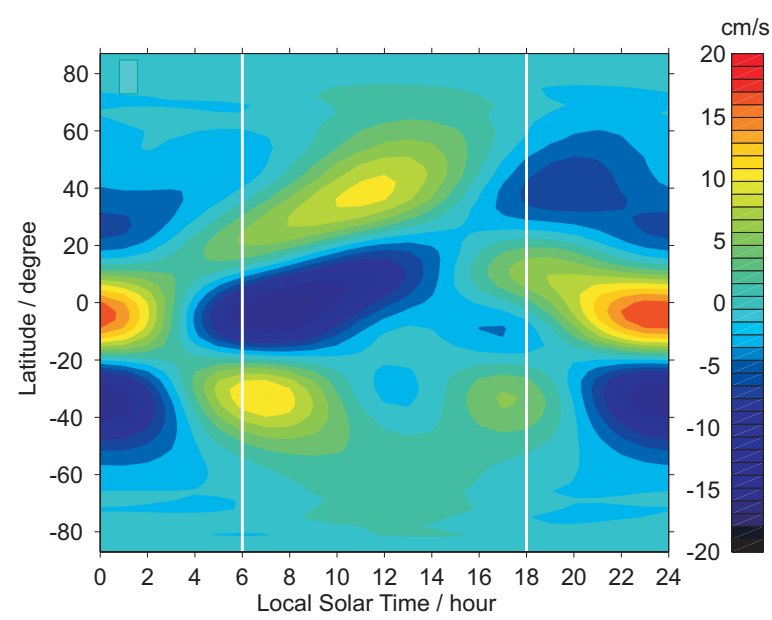

Fig. 6. Vertical tidal velocity at $90.6 \mathrm{~km}$ during September, as a function of local time (LT) and latitude. Data taken from the GSWM (Hagan and Forbes, 2002). The vertical white lines indicate the approximate local times of the Odin measurements.

control on the sodium chemistry through reaction 4 and the reactions:

$\mathrm{NaO}_{2}+\mathrm{O} \rightarrow \mathrm{NaO}+\mathrm{O}_{2}$

$\mathrm{NaO}+\mathrm{O} \rightarrow \mathrm{Na}+\mathrm{O}_{2}$

The resulting decrease in the rates of Reactions (4), (7) and (8) then reinforce the conversion of $\mathrm{Na}$ to $\mathrm{NaO}_{2}$ and $\mathrm{NaHCO}_{3}$, which could explain the observed depletion of $\mathrm{Na}$ atoms at 06:00 LT (Fig. 5). However, these tidal effects are quite complex and a detailed chemical-dynamical model is required to understand this very interesting phenomenon properly.

Finally, Fig. 5 shows that at mid- to high latitudes $\left(\sim 25^{\circ}-\right.$ $70^{\circ}$ ), the smaller diurnal variation of the Na layer is actually reversed from the tropics i.e. the density below $90 \mathrm{~km}$ is higher at 06:00 LT compared with 18:00 LT. This is consistent with the vertical tidal wind direction also reversing in phase between the tropics and latitudes greater than about $20^{\circ}$, as shown in Fig. 6.

\section{Polar depletion of the Na layer}

The global minimum of the Na column abundance occurs at high latitudes during summer, and can be an order of magnitude lower than the maximum (Fig. 1). At the same time, the FWHM width of the $\mathrm{Na}$ layer in the summertime polar region is also a minimum (Fig. 4a), about half the width of the layer during winter or at lower latitudes. In this section the reasons for this extreme seasonal behavior in the polar regions will be discussed in more detail.

Figure 7 displays the sodium density profiles at mid- and high latitudes between March and September, straddling the 

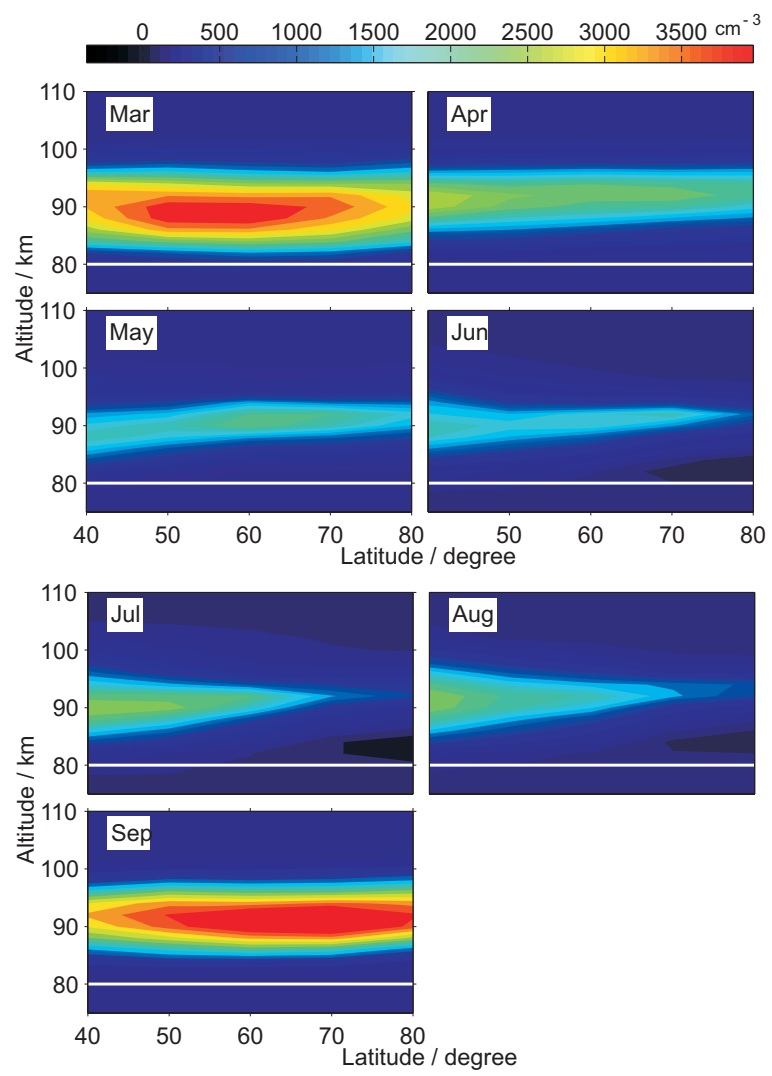

Fig. 7. Contour plots of the $\mathrm{Na}$ density height profile (units: atom $\mathrm{cm}^{-3}$ ) between $40^{\circ}$ and $80^{\circ} \mathrm{N}$, during the months March to September, 2004.

NH summer solstice. A white horizontal line has been drawn on each of the plots at $80 \mathrm{~km}$ to aid the eye in observing changes to the underside of the Na layer. Figure 8 compares the month-to-month variation of the mean $\mathrm{Na}$ layer profiles at latitudes of $40^{\circ} \mathrm{N}$ and $80^{\circ} \mathrm{N}$, from spring equinox to the summer solstice. The undersides of the Na profiles during the solstice show a clear cutoff below $85 \mathrm{~km}$.

Previous ground-based lidar measurements have observed the very low minimum $\mathrm{Na}$ abundance in the Arctic region during summer (e.g. Gardner et al., 1988; von Zahn et al., 1988; Gardner et al., 2005). Recent research has focused on the removal of metal atoms (and their compounds) on the surfaces of ice particles (Lübken and Höffner, 2004; Plane et al., 2004), following a laboratory study which demonstrated that $\mathrm{Fe}, \mathrm{Na}$ and $\mathrm{K}$ atoms are all removed very efficiently on low-temperature ice surfaces (Murray and Plane, 2005). Simultaneous measurements of mesospheric Na, PMCs and polar mesosphere summer echoes (PMSE) (She et al., 2006) also found that polar Na depletion is highly correlated with PMCs, whereas the smaller-sized ice particles detected by radar as PMSE exhibit a weaker anti-correlation with the $\mathrm{Na}$ density around $85 \mathrm{~km}$.

The satellite retrievals enable the full process of polar $\mathrm{Na}$
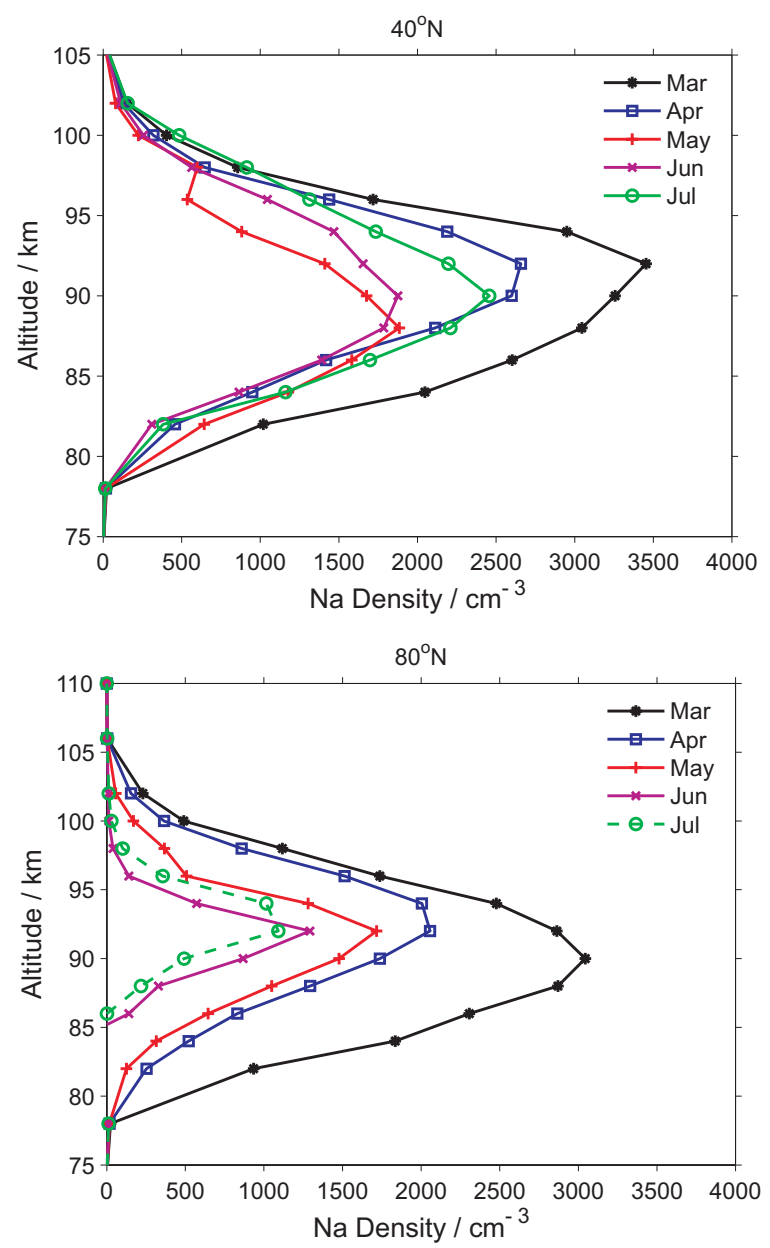

Fig. 8. Monthly Na profiles from March to July, 2004, at a latitude of (a) $40^{\circ} \mathrm{N}$, and (b) $80^{\circ} \mathrm{N}$.

layer depletion to be tracked. In April and May, the Na layer shifts gradually to a summertime profile, mainly due to the temperature-dependent $\mathrm{Na}$ chemistry discussed above, where a larger fraction of the sodium is in the form of $\mathrm{NaHCO}_{3}$. In June, July and August the underside of the Na layer exhibits a sharp cut-off at about $85 \mathrm{~km}$. In the June and July profiles, the lower edge of the layer gradually rises northwards from $\sim 50^{\circ} \mathrm{N}$. The Na depletion on the underside disappears abruptly in September.

In a very recent paper (Petelina et al., 2006), the occurrence of PMC was derived from the same OSIRIS spectra that we have used to retrieve the $\mathrm{Na}$ density profiles. The results can therefore be used to explore the relationship between them. Although it is difficult to determine precisely the altitude of a PMC when viewed in the limb, the PMC peak heights were found to be located mostly between 83 $84 \mathrm{~km}$ (Petelina et al., 2006). PMCs were observed from $50^{\circ} \mathrm{N}$ to higher latitudes, and from the beginning of June until the end of August. The clouds appeared most frequently immediately after the summer solstice (Petelina et al., 2006). 
These PMC statistics are in complete accord with the polar Na profiles: the underside of the Na layer below $85 \mathrm{~km}$ disappears completely from June until the end of August. In fact, since the bottom of the Na layer in polar regions is very sensitive to the presence of PMCs, it may be useful as an indicator of the presence of PMCs which are not optically detectable.

\section{Conclusions}

This paper demonstrates the ability of our new algorithm (Gumbel et al., 2007), based on optimal estimation theory (Rodgers, 2000), to retrieve absolute Na density profiles from limb-scanning measurements of the $\mathrm{Na} D$-line radiance at $589 \mathrm{~nm}$ in the dayglow. These global measurements provide a very useful complement to ground-based lidar observations. Particular highlights of the present data set are the first extensive set of observations of the Na layer in the equatorial region. We find that the layer exhibits little seasonal variability, but has a very marked diurnal variation, particularly during the equinoxes. This is almost certainly driven by the diurnal tide. The measurements in the polar regions confirm the relationship between depletion of $\mathrm{Na}$ below $85 \mathrm{~km}$ and the presence of PMCs during the summer at latitudes above $50^{\circ}$.

Acknowledgements. Z. Fan acknowledges contributions from the Universities of East Anglia, Stockholm and Saskatoon towards his PhD studentship.

Edited by: W. Ward

\section{References}

Bernard, R.: The identification and the origin of atmospheric sodium, Astrophysical Journal, 89, 133-135, 1939.

Blamont, J. E. and Donahue, T. M.: The Dayglow of the Sodium D Lines, J. Geophys. Res., 66, 1407-1427, 1961.

Bowman, M. R., Gibson, A. J., and Sandford, M. C.: Atmospheric Sodium Measured by a Tuned Laser Radar, Nature, 221, 456458, 1969.

Chamberlain, J. W.: Resonance Scattering by Atmospheric Sodium. 1. Theory of the Intensity Plateau in the Twilight Airglow, J. Atmos. Terr. Phys., 9, 73-89, 1956.

Chapman, S.: Notes on atmospheric sodium, J. Astrophys., 90, 309-316, 1939.

Clemesha, B. R., Kirchhoff, V. W. K. H., and Simonich, D. M.: Concerning the Seasonal-Variation of the Mesospheric Sodium Layer at Low-Latitudes, Planet. Space Sci., 27, 909-910, 1979.

Clemesha, B. R., Simonich, D. M., Batista, P. P., and Kirchhoff, V. W. K. H.: The diurnal variation of atmospheric sodium, J. Geophys. Res., 87, 181-186, 1982.

Clemesha, B. R., Sahai, Y., Simonich, D. M., and Takahashi, H.: Nighttime Na-D Emission Observed from a Polar-Orbiting DMSP Satellite - Comment, J. Geophys. Res., 95, 6601-6606, 1990.
Clemesha, B. R., Simonich, D. M., Batista, P. P., Vondrak, T., and Plane, J. M. C.: Negligible long-term temperature trend in the upper atmosphere at 23o S, J. Geophys. Res., 109, D05302, doi:05310.01029/02003JD004243, 2004.

Cox, R. M. and Plane, J. M. C.: An ion-molecule mechanism for the formation of neutral sporadic Na layers, J. Geophys. Res., 103, 6349-6359, 1998.

Cox, R. M., Self, D. E., and Plane, J. M. C.: A study of the reaction between $\mathrm{NaHCO} 3$ and $\mathrm{H}$ : Apparent closure on the chemistry of mesospheric Na, J. Geophys. Res., 106, 1733-1739, 2001.

Donahue, T. M. and Meier, R. R.: Distribution of Sodium in Daytime Upper Atmosphere as Measured by a Rocket Experiment, J. Geophys. Res., 72, 2803-2821, 1967.

Fussen, D., Vanhellemont, F., Bingen, C., Kyrola, E., Tamminen, J., Sofieva, V., Hassinen, S., Seppala, A., Verronen, P., Bertaux, J. L., Hauchecorne, A., Dalaudier, F., Renard, J. B., Fraisse, R., d'Andon, O. F., Barrot, G., Mangin, A., Theodore, B., Guirlet, M., Koopman, R., Snoeij, P., and Saavedra, L.: Global measurement of the mesospheric sodium layer by the star occultation instrument GOMOS, Geophys. Res. Lett., 31, L24110, doi:24110.21029/22004GL021618, 2004.

Gardner, C. S., Senft, D. C., and Kwon, K. H.: Lidar Observations of Substantial Sodium Depletion in the Summertime Arctic Mesosphere, Nature, 332, 142-144, 1988.

Gardner, C. S., Plane, J. M. C., Pan, W., Vondrak, T., Murray, B. J., and Chu, X.: Seasonal variations of the $\mathrm{Na}$ and Fe layers at the South Pole and their implications for the chemistry and general circulation of the polar mesosphere, J. Geophys. Res., 110, D10302, doi.10310.11029/12004JD005670, 2005.

Gibson, A. J. and Sandford, M. C. W.: The seasonal variation of the night-time sodium layer, J. Atmos. Terr. Phys., 33, 1675-1684, 1971.

Gibson, A. J. and Sandford, M. C. W.: Daytime Laser Radar Measurements of Atmospheric Sodium Layer, Nature, 239, 509-511, 1972.

Gumbel, J., Fan, Z. Y., Waldemarsson, T., Stegman, J., Llewellyn, E. J., She, C.-Y., and Plane, J. M. C.: Retrievals of global mesospheric sodium densities from the Odin satellite, Geophys. Res. Lett., 34, L04813, doi:04810.01029/02006GL028687, 2007.

Hagan, M. E. and Forbes, J. M.: Migrating and nonmigrating diurnal tides in the middle and upper atmosphere excited by tropospheric latent heat release, J. Geophys. Res., 107, 4754, doi:4710.1029/2001JD001236, 2002.

Hunten, D. M.: A study of sodium in twilight. I. Theory, J. Atmos. Terr. Phys., 5, 44-56, 1954.

Hunten, D. M.: Spectroscopic studies of the twilight airglow, Space Sci. Rev., 6, 493-573, 1967.

Hunten, D. M., Jones, A. V., Ellyett, C. D., and , McLauchlan, E. C.: Sodium twilight at Christchurch, New Zealand, J. Atmos. Terr. Phys., 26, 67-76, 1964.

Kane, T. J., Hostetler, C. A., and Gardner, C. S.: Horizontal and Vertical Structure of the Major Sporadic Sodium Layer Events Observed During ALOHA-90, Geophys. Res. Lett., 18, 13651368, 1991.

Kirchhoff, V. and Clemesha, B. R.: The Atmospheric Neutral Sodium Layer .2. Diurnal Variations, J. Geophys. Res., 88, 442 450, 1983.

Livesey, N. J., Read, W. G., Froidevaux, L., Waters, J. W., Santee, M. L., Pumphrey, H. C., Wu, D. L., Shippony, Z., and Jarnot, 
R. F.: The UARS microwave limb sounder version 5 data set: Theory, characterization, and validation J. Geophys. Res., 108, 4378, doi:4310.1029/2002JD002273, 2003.

Llewellyn, E. J., Lloyd, N. D., Degenstein, D. A., Gattinger, R. L., Petelina, S. V., Bourassa, A. E., Wiensz, J. T., Ivanov, E. V., McDade, I. C., Solheim, B. H., McConnell, J. C., Haley, C. S., von Savigny, C., Sioris, C. E., McLinden, C. A., Griffioen, E., Kaminski, J., Evans, W. F. J., Puckrin, E., Strong, K., Wehrle, V., Hum, R. H., Kendall, D. J. W., Matsushita, J., Murtagh, D. P., Brohede, S., Stegman, J., Witt, G., Barnes, G., Payne, W. F., Piche, L., Smith, K., Warshaw, G., Deslauniers, D. L., Marchand, P., Richardson, E. H., King, R. A., Wevers, I., McCreath, W., Kyrola, E., Oikarinen, L., Leppelmeier, G. W., Auvinen, H., Megie, G., Hauchecorne, A., Lefevre, F., de La Noe, J., Ricaud, P., Frisk, U., Sjoberg, F., von Scheele, F., and Nordh, L.: The OSIRIS instrument on the Odin spacecraft, Canadian Journal of Physics, 82, 411-422, 2004.

Lübken, F. J. and Höffner, J.: Experimental evidence for ice particle interaction with metal atoms at the high latitude summer mesopause region, Geophys. Res. Lett., 31, L08103, 08110.01029/02004GL019586, 2004.

Megie, G. and Blamont, J. E.: Laser Sounding of Atmospheric Sodium Interpretation in Terms of Global Atmospheric Parameters, Planet. Space Sci., 25, 1093-1109, 1977.

Murray, B. J. and Plane, J. M. C.: Uptake of Fe, Na and K atoms on low-temperature ice: implications for metal atom scavenging in the vicinity of polar mesospheric clouds, Phys. Chem. Chem. Phys., 7, 3970-3979, 2005.

Murtagh, D., Frisk, U., Merino, F., Ridal, M., Jonsson, A., Stegman, J., Witt, G., Eriksson, P., Jimenez, C., Megie, G., de la Noe, J., Ricaud, P., Baron, P., Pardo, J. R., Hauchcorne, A., Llewellyn, E. J., Degenstein, D. A., Gattinger, R. L., Lloyd, N. D., Evans, W. F. J., McDade, I. C., Haley, C. S., Sioris, C., von Savigny, C., Solheim, B. H., J. C. McConnell, K. Strong, E. H. Richardson, Leppelmeier, G. W., Kyrola, E., Auvinen, H., and Oikarinen, L.: An overview of the Odin atmospheric mission, Can. J. Phys., 80, 309-319, 2002.

Newman, A. L.: Nighttime Na D emission observed from a polarorbiting DMSP satellite, J. Geophys. Res., 93, 4067-4075, 1988.

Petelina, S. V., Llewellyn, E. J., Degenstein, D. A., and Lloyd, N. D.: Odin/OSIRIS limb observations of polar mesospheric clouds in 2001-2003, J. Atmos. Solar-Terr. Phys., 68, 42-55, 2006.

Picone, J. M., Hedin, A. E., Drob, D. P., and Aikin, A. C.: NRLMSISE-00 empirical model of the atmosphere: Statistical comparisons and scientific issues, J. Geophys. Res., 107, 1468, doi:1410.1029/2002JA009430, 2002.

Plane, J. M. C.: Atmospheric chemistry of meteoric metals, Chem. Rev., 103, 4963-4984, 2003.

Plane, J. M. C.: A time-resolved model of the mesospheric Na layer: constraints on the meteor input function, Atmos. Chem. Phys., 4, 627-638, 2004,

http://www.atmos-chem-phys.net/4/627/2004/.
Plane, J. M. C., Cox, R. M., Qian, J., Pfenninger, W. M., Papen, G. C., Gardner, C. S., and Espy, P. J.: Mesospheric Na layer at extreme high latitudes in summer, J. Geophys. Res., 103, 63816389, 1998.

Plane, J. M. C., Gardner, C. S., Yu, J. R., She, C. Y., Garcia, R. R., and H. C.,: Mesospheric Na layer at $40^{\circ} \mathrm{N}$ : Modeling and observations, J. Geophys. Res., 104, 3773-3788, 1999.

Plane, J. M. C., Murray, B. J., Chu, X., and Gardner, C. S.: Removal of Meteoric Iron on Polar Mesospheric Clouds, Science, 304, 426-428, 2004.

Portnyagin, Y. I., Solovjova, T. V., Makarov, N. A., Merzlyakov, E. G., Manson, A. H., Meek, C. E., Hocking, W., Mitchell, N., Pancheva, D., Hoffmann, P., Singer, W., Murayama, Y. Igarashi,, K., Forbes, J. M., Palo, S., Hall, C., and Nozawa, S.: Monthly mean climatology of the prevailing winds and tides in the Arctic mesosphere/lower thermosphere, Annal. Geophys., 22, 33953410, 2004.

Rodgers, C. D.: Inverse methods for atmospheric sounding : theory and practice, 238 pp., World Scientific, Singapore, 2000.

Russell, J. P., Ward, W. E., Lowe, R. P., Roble, R. G., Shepherd, G. G., and Solheim, B.: Atomic oxygen profiles (80 to $115 \mathrm{~km}$ ) derived from Wind Imaging Interferometer/Upper Atmospheric Research Satellite measurements of the hydroxyl and greenline airglow: Local time-latitude dependence, J. Geophys. Res., 110, D15305, doi:15310.11029/12004JD005570, 2005.

She, C. Y., Chen, S. S., Hu, Z. L., Sherman, J., Vance, J. D., Vasoli, V., White, M. A., Yu, J. R., an Krueger, D. A.: Eight-year climatology of nocturnal temperature and sodium density in the mesopause region ( 80 to $105 \mathrm{~km}$ ) over Fort Collins, $\mathrm{CO}\left(41^{\circ} \mathrm{N}\right.$, $105^{\circ}$ W), Geophys. Res. Lett., 27, 3289-3292, 2000.

She, C. Y., Williams, B. P., Hoffmann, P., Latteck, R., Baumgarten, G., Vance, J. D., Fiedler, J., Acott, P., Fritts, D. C., and Lübken, F. J.: Simultaneous observation of sodium atoms, NLC and PMSE in the summer mesopause region above ALOMAR, Norway $\left(69^{\circ} \mathrm{N}, 12^{\circ}\right.$ E), J. Atmos. Solar-Terr. Phys., 68, 93-101, 2006.

Slipher, V. M.: Emissions in the spectrum of the light of the night sky, Publ. Astron. Soc. Pacific, 41, 262-265, 1929.

States, R. J. and Gardner, C. S.: Structure of the mesospheric Na layer at $40^{\circ} \mathrm{N}$ latitude: Seasonal and diurnal variations, J. Geophys. Res., 104, 11783-11 798, 1999.

Tilgner, C. and von Zahn, U.: Average Properties of the Sodium Density Distribution as Observed at $69^{\circ} \mathrm{N}$ Latitude in Winter, J. Geophys. Res., 93, 8439-8454, 1988.

von Zahn, U., Hansen, G., and Kurzawa, H.: Observations of the sodium layer at high latitudes in summer, Nature, 331, 594-596, 1988.

Xu, J. Y., Smith, A. K., and Wu, Q.: A retrieval algorithm for satellite remote sensing of the nighttime global distribution of the sodium layer J. Atmos. Solar-Terr. Phys., 67, 739-748, 2005 